\title{
Effect of weathered surface crust layer on stability of Muar trial embankment
}

\begin{abstract}
This paper attempts to evaluate the effect of surface crust layer on the stability and deformation behavior of embankment. A full-scale case history trial embankment constructed on Muar flat in the valley of the Muar River in Malaysia was modeled and analyzed. The Muar trial embankment was simulated in two- and three-dimension (2-D and 3-D) utilizing finite element programs PLAXIS 2-D AND PLAXIS 3-D FOUNDATION, using stagedconstruction procedure. Sensitivity analysis was performed by varying the thickness of weathered crust layer beneath the embankment fill, i.e., three models of embankment with no surface crust, $1 \mathrm{~m}$ surface crust and $2 \mathrm{~m}$ surface crust layer. Predictions were made for the vertical and the horizontal displacements of the embankment. Factor of safety for each meter increase in the embankment height was defined until the failure is reached. It is concluded that the bearing capacity of the ground and the deformation behavior of the embankment were sensitive to the thickness of the weathered crust layer. The surface crust layer has a positive effect on the stability of the embankment and consequently reduces the settlement and increases the failure height of the embankment fill up to $37 \%$.
\end{abstract}

Keyword: Muar trial embankment; Surface crust layer; Finite element analysis; Stability analysis; Safety factor 